\title{
A ficção televisiva e o galã de novela em zona de fronteira entre o machismo e o feminismo: um estudo de caso do galã José Mayer
}

\section{TV FICTION AND THE HEARTTHROBS FROM BRAZILIAN TELENOVELAS BETWEEN FEMINISM AND MALE CHAUVINISM: A STUDY CASE ON JOSÉ MAYER}

\section{João Nemi Neto}

Docente do Latin American and Iberian Cultures Department da Columbia University, Nova York, Estados Unidos. Doutor em Hispanic and Luso-Brazilian Literatures and Languages pelo Graduate Center/City University of New York. Pesquisador do Grupo de Estudos de Linguagens e Discursos nos Meios de Comunicação (GELiDis) da Escola de Comunicação e Artes da Universidade de São Paulo (ECA-USP).

E-mail: jn2395@columbia.edu

\section{Daniela Jakubaszko}

Docente da Escola de Comunicação da Universidade Municipal de São Caetano do Sul (USCS). Doutora em Ciências da Comunicação pela Escola de Comunicações e Artes da Universidade de São Paulo (ECA-USP). Pesquisadora do Grupo de Estudos de Linguagens e Discursos nos Meios de Comunicação (GELiDis) da ECA-USP.

E-mail: ocadani@yahoo.com

Recebido em 2 de agosto de 2017. Aprovado em 14 de setembro de 2017.

\section{Resumo}

Este artigo apresenta um estudo de caso do galã José Mayer com o objetivo de refletir como o tempo histórico presente, que problematiza o machismo, é capaz de pressionar o gênero teledramatúrgico a transformar padrões composicionais fundamentais. Por meio de análise em perspectiva dialógica, conclui-se que é possível registrar mudanças significativas na construção do galã, assim como nas formas composicionais para o happy ending. O diálogo que se forma nas fronteiras entre ficção e realidade pressiona as formas estéticas e as práticas culturais a se transformarem.

Palavras-chave: Telenovela brasileira. Galã de telenovela. Amor romântico.

$122 \frac{\text { Comunicação \& Inovação, PPGCOM/USCS }}{\text { v. 18, n. 38 (122-140) set-dez } 2017}$ 


\section{Abstract}

This article presents a case study on the heartthrob leading man José Mayer. By problematizing machismo we discuss in which ways our time is able to press the tele-dramaturgical genre to transform fundamental standards. Through a dialogical analysis, we conclude that it is feasible to see significant changes in the composition of the heartthrob leading man and in the happy endings." The dialogue between fiction and reality forces changes in the aesthetic forms and cultural practices.

Keywords: Brazilian telenovelas. Heartthrob. Romantic love.

\section{Introdução}

Há mais de 50 anos, a telenovela brasileira, seus personagens e respectivos conflitos vêm se modificando junto com a sociedade brasileira. A memória das telenovelas se mantém viva e atuante no ambiente social, se acha entrelaçada com as memórias individuais e coletivas de seus interlocutores e com a história do país (MOTTER, 2000-2001; 2003; JAKUBASZKO, 2008).

Por mais que se questione o vigor e a adequação do gênero teledramatúrgico, no qual se verificam oscilações e perdas de audiência, ele se reinventa enquanto gênero e formato (LOPES; GÓMEZ, 2016) e se mantém forte enquanto discurso capaz de captar e expressar os temas e conflitos socioculturais brasileiros em tempos de globalização (JAKUBASZKO, 2008; HAMBURGER, 2005).

Desde a década de 1970, as telenovelas, sobretudo as do horário nobre, abordam temas e preocupações contemporâneas (JAKUBASZKO, 2008). Nas duas últimas décadas vemos ampliar-se a tendência ao debate de temas de importância social nas tramas principais e secundárias. A audiência ainda se reconhece, se identifica e se atualiza com as histórias contadas. Totalmente integrada à nossa cultura, a telenovela acumula e produz memória, conhecimento, participa dos diálogos sociais contribuindo para a formulação de consensos. Seu estudo é indispensável.

Ao longo dos anos, a telenovela foi se constituindo e se fortalecendo como um gênero do discurso (BAKHTIN, 2006) de grande importância na cultura brasileira. A telenovela pode ser estudada como um gênero do discurso porque tem formas típicas que governam a sua construção, segue e reproduz padrões, fortalece um estilo próprio para o formato televisivo, além do estilo de cada roteirista e do diálogo que se forma entre as diferentes histórias e autores (JAKUBASZKO, 2010). Enquanto gênero também carrega 
memória, herda de suas referências literárias inúmeras características e elementos que se combinam, intercambiam e se transformam com o tempo. A partir da década de 1970, a telenovela brasileira recebe ainda influências do circo, do rádio, do teatro, do cinema, distanciando-se da fórmula simplista do melodrama que polariza bem e mal absolutos ao construir personagens e conflitos de maior densidade e proximidade com a realidade do espectador. $\mathrm{O}$ gênero ganha continuamente novas feições para se adequar ao presente e à realidade vivida pelo telespectador, já que atua como importante mediador das relações culturais (MARTÍN-BARBERO, 2015). É que a evolução de um gênero acontece por meio do dialogismo, em permanente interação com a realidade social:

A telenovela vem mostrando plasticidade para incorporar elementos de outros gêneros ficcionais e não ficcionais, além de incorporar elementos da realidade que lhe garantem a manutenção de intenso diálogo com o cotidiano social concreto do país. Situada no passado ou no presente, tratando de temas históricos ou puramente ficcionais, a telenovela incorpora em sua narrativa elementos de diversos sistemas semióticos e fala do hoje, rearticulando dados da memória coletiva na produção de sentidos renovados e se firma como documento histórico, lugar de memória, refratando, pela ótica ficcioautoral, um momento do processo de desenvolvimento da sociedade brasileira. (MOTTER, 2004, p. 251-252)

As relações de gênero e as narrativas da emancipação feminina, além de constantemente tematizadas, recebem espaço privilegiado nas tramas. Mesmo assim emergem as contradições: a cultura machista ainda impregna os personagens, conflitos e soluções de valores, critérios e julgamentos que obedecem à lógica patriarcal. Herdeira do folhetim, a telenovela formatou-se de modo a compor

Uma mistura folhetinesca temperada pelo imaginário da família patriarcal em mutação - é tipicamente brasileira. A abertura do folhetim para o real-histórico (para a ideologia) permite a incorporação de informações sobre a dinâmica modernizadora da sociedade urbana nacional e relança continuamente ao nível das famílias (grupos receptores naturais da telenovela) doutrinas e ideias correntes (liberação sexual, novas formas de relacionamento amoroso, novos regimes de casamento), assim como "ensina” a consumir. (SODRÉ apud CAVALCANTE, 2005, p. 72)

A explosão de textos na cultura que problematizam as questões de gênero, a dominação masculina e as relações assimétricas de poder, exerce pressão sobre o gênero teledramatúrgico no sentido de transformar seus padrões composicionais? O galã de novela está moldado conforme a lógica patriarcal? Ele pode se tornar "feminista"? O "gaylã" seria um tipo viável? A busca pelo amor romântico continuará sendo o fio condutor das 
narrativas? Se as regras do folhetim são flexíveis para que ele possa expressar o espírito de cada época, a ficção televisiva transformaria seus padrões composicionais para se aproximar do ponto de vista das lutas feministas e LGBTQ?

As representações de histórias de mulheres, de processos emancipatórios e empoderamento feminino, de diferentes vivências de gênero e de amor, de ruptura com a normatividade heterossexual e com a prevalência do modelo hegemônico de masculinidade vêm ganhando protagonismo nas tramas. Tais narrativas tornaram-se marcas da telenovela brasileira atual. Pretende-se investigar, a partir de uma perspectiva dialógica (BAKHTIN, 2006; JAKUBASZKO, 2010; NEMI, 2015), como o discurso que se forma nas fronteiras entre ficção e realidade do tempo histórico presente pressiona as formas estéticas e as práticas culturais a se transformarem. Acreditamos que seja possível registrar mudanças significativas na construção do galã, assim como nas formas composicionais para o happy ending. Para tanto, fizemos um estudo de caso do galã José Mayer, considerando também outros personagens, telenovelas e diversas manifestações discursivas do ambiente sociocultural brasileiro.

\section{Zé Mayer, um galã em zona de fronteira entre ficção e realidade}

Existe exemplo de telenovela sem galã? Um tipo indispensável: todos são galantes, charmosos, de porte elegante. As mulheres suspiram por eles. $\mathrm{Na}$ faixa dos 30 aos 60 anos $^{1}$, quando heróis, também devem ser honrados e íntegros. Correspondem ao tipo hegemônico, ao homem "ideal": adulto branco cis heterossexual.

Galã. [do fr. Galant] S.m. 1. Teat. e Cin. Personagem ou ator que representa o herói de boa aparência e atitudes, inteligente e corajoso, e que exerce o papel decisivo nas intrigas de amor.

2. Homem belo e elegante. 3. Fam. Namorador, galanteador. (GALÃ, 2014, grifos nossos)

José Mayer é um dos galãs mais reconhecidos da TV brasileira. Até hoje participou de 24 novelas, 4 minisséries e uma série ${ }^{2}$. Protagonista na maioria delas, já contracenou com as mais belas e expressivas atrizes do casting da Rede Globo, sempre considerado

1 O site do Gshow relembra alguns galãs da década de 1980 e José Mayer está ente eles. A reportagem afirma que ele dominava a ala dos galãs. Disponível em: <goo.gl/aJajKU>. Acesso em: 12 jul. 2017. Outra reportagem que lembra os galãs de novela está disponível em: <goo.gl/eNvdCg>. Acesso em: 12 jul. 2017. Para conferir os galãs da nova geração, veja: <goo.gl/DnC4Fk>. Acesso em: 12 jul. 2017.

2 Cf.: <goo.gl/DCYdVs>. Acesso em: 22 jul. 2017. 
um grande conquistador ${ }^{3}$. De acordo com o registro de um blog sobre televisão ${ }^{4}$, em sua carreira de galã contracenou com Maria Zilda, Regina Duarte, Susana Vieira, Lília Cabral, Carolina Ferraz, Vera Fischer, Helena Ranaldi, Adriana Esteves. Recusou a Íris de Deborah Secco em Laços de família (Manoel Carlos, TV Globo, 2000-2001, 21h). Viveu um triângulo amoroso com Helena Ranaldi e Mel Lisboa em Presença de Anita (Manoel Carlos, TV Globo, 2001, 22h30). Envolveu-se com Carolina Kasting, Camila Pitanga e Christiane Torloni em Mulheres apaixonadas (Manoel Carlos, TV Globo, 2003, 21h). Na novela seguinte, Páginas da vida (Manoel Carlos, TV Globo, 2006-2007, 21h), relaciona-se com quatro mulheres durante a trama. Não escaparam Juliana Paes, na já citada A favorita, e Marília Gabriela em Senhora do destino, sua única atuação em telenovela (Aguinaldo Silva, TV Globo, 2004-2005, 21h). Certamente estamos esquecendo alguma atriz, pedimos perdão ao leitor, mas não é objetivo deste trabalho realizar um levantamento exaustivo. Uma reportagem da revista Conta Mais (n. 410 - 27 out. 2008) rememora outros pares amorosos do ator e conta "quase 3 mil beijos em cena", são "Três décadas de grandes conquistas" (apud JAKUBASZKO, 2010, p.277-278). Agora, são quase quatro décadas.

FOLHA - O que te faz um galã?

MAYER - Bom, inicialmente, masculinidade, né? É preciso ser masculino. É preciso exalar masculinidade à primeira vista. Talvez tenham de mim essa primeira impressão. $\mathrm{O}$ meu movimento, meu jeito de olhar, minha fala, meu tom de voz, talvez inspirem... é a atitude masculina, basicamente. E o exercício da minha profissão, que me deu uma certa experiência, um certo, digamos, charme, no sentido de capacidade de tornar interessante um trabalho que estou apresentando. Isso é domínio técnico. Talvez o charme venha do ator, não sei se vem do homem. Será? Quem sabe...5 (SER..., 2009)

Será que José Mayer e os galãs em geral atraem porque "exalam masculinidade à primeira vista"? Segundo entendemos, tanto os galãs quanto os atores que os representam podem ser considerados exemplos de masculinidade. E qual é a masculinidade proposta pelo galã de novela? Há mudanças em curso? Uma reportagem do Fantástico, em 13 de setembro de 2009, que também rememora diversas parceiras de Mayer, apresenta definições de masculinidade de Manoel Carlos e do próprio Mayer:

3 A trajetória do galã está disponível em: <goo.gl/rA6jL5>. Acesso em: 12 jul. 2017. Para mais informações sobre a carreira do ator: $<$ goo.gl/jD6qEQ $>$. Acesso em: 12 jul. 2017; $<$ goo.gl/66mWQe $>$. Acesso em: 12 jul. 2017.

4 Disponível em: <goo.gl/9y6XLM>. Acesso em: 12 jul. 2017.

5 Disponível em: <goo.gl/bY3mxp>. Acesso em: 13 nov. 2017.

$126 \frac{\text { Comunicação \& Inovação, PPGCOM/USCS }}{\text { v. 18, n. } 38 \text { (122-140) set-dez } 2017}$ 
Manoel Carlos, autor da novela "Viver a vida", revela: as atrizes adoram fazer par romântico com ele. "O Zé Mayer é uma unanimidade, como homem, expressão artística do homem, do sujeito viril, romântico sem ser meloso, sem ser chorão. É o homem que, pela nossa experiência com relação à pesquisa e conhecimento, é o mais desejado por todas as mulheres em qualquer faixa de idade".

Mesmo sendo preferência nacional, José Mayer diz que o sucesso não está na sua beleza. "Galã significa homem bonito, gostoso. Eu não me acho bonito, realmente não me acho bonito. Eu me acho, assim, eu me acho interessante como ator [...]. Para os homens que querem ser sedutores: em primeiro lugar precisam melhorar seu conteúdo mental, porque as mulheres dão muito valor a isso, sabia? Felizmente, as mulheres julgam beleza de maneira muito subjetiva. Elas conseguem ver beleza em um homem feio de bom conteúdo, talvez seja isso que aconteça comigo", diz o ator. (Apud JAKUBASZKO, 2010, p. 274)

Notamos nos discursos que ser masculino é ser conquistador. O galã é bonito, mas também precisa ter a cabeça feita; deve ser desejado por mulheres de todas as idades, ser viril, romântico, mas sem ser chorão ou meloso. Interessante notar que o galã é "conquistador", desejado por todas as mulheres, mas apenas uma irá conquistar seu coração. Depois que um herói encontra sua heroína, a tendência é que se dedique à fidelidade que o amor romântico preconiza. A "fidelidade" associa-se à virtude masculina, ao menos segundo o olhar da tradição romanesca. Na construção da masculinidade do herói estão as virtudes e atributos que um homem "deve" ter, enquanto o vilão mostra as que ele não deve ter. Sua narrativa pode trazer uma proposta de como regenerar um homem, transformando defeitos em virtudes (JAKUBASZKO, 2010).

O galã fica tão colado à imagem do ator que quando ele interpreta outros tipos provoca estranhamento na audiência, fabulações na imprensa e redes sociais. As revistas especializadas em telenovela, alguns programas de televisão e diversos blogs comentaram sobre a proximidade do aniversário de 60 anos de José Mayer enquanto interpretava Augusto César em A favorita (João Emanuel Carneiro, TV Globo, 20082009, 21h), um “maluco beleza", não muito identificado com o tipo galã. Surgem comparações, diferenças e semelhanças entre ator e personagem, e novas relações de sentido entre os cruzamentos do personagem de então com os anteriores (JAKUBASZKO, 2010). A memória dos textos emerge para acrescentar sentido ao personagem que estiver sendo interpretado no momento. Assim, mesmo quando o personagem quebra com o rótulo tradicional de galã, o título, ou a expectativa, reaparece. Em Império (Aguinaldo Silva, TV Globo, 2014-2015, 21h), José Mayer interpretou Leandro, um bissexual, e foi bastante elogiado pelo "jeito macho" de seu personagem. Como provoca Thiago Araújo, 
diferentemente da atuação preguiçosa de Betti, Mayer e Toledo não fazem nesta cena qualquer ação que faça o telespectador apitar mentalmente o alerta "é bicha!". Pelo contrário, eles dão um show e se seguirem por este caminho vão desafiar os babacas que perguntam "onde foram parar os machos”. José Mayer está aí... (ARAÚJO, 2014, aspas do autor) ${ }^{6}$

Vale ressaltar a expressão usada pelo crítico: “eles dão um show”. A efeminofobia (NEMI NETO, 2015; 2016) presente no texto é latente. José Mayer, mesmo na relação homossexual, permanece o "macho". O galã não perde a pose.

Há mais um exemplo em Fina estampa (Aguinaldo Silva, TV Globo, 2011-2012, 21h): o personagem Pereirinha é cômico, de trama secundária, malandro oportunista que conquista a bela e rica Tereza Cristina (Christiane Torloni) ${ }^{7}$. O galã deveria ser o contrário do bobo, dos personagens de núcleo cômico. Entretanto, a memória dos textos emerge novamente e o ator-galã empresta ao personagem cômico o aspecto de virilidade. Ao mesmo tempo, o traço "conquistador" parece cair de moda como atributo de galã.

Reproduzimos abaixo trechos do Dossiê José Mayer: por que ele merece o \#zemayerfacts, escrito na época de Viver a vida (Manoel Carlos, TV Globo, 2010, 21h) quando se tornou o segundo nome mais comentado do mundo no Twitter durante duas semanas, depois de conquistar a Helena de Taís Araújo, na primeira semana da novela:

não há como ignorar sua fama de conquistador - fato que, inclusive, rendeu matéria exclusiva no Fantástico deste domingo. [...] tornou-se um dos nomes mais citados da Internet nesta semana. [...] surgiu o \#zemayerfacts, em homenagem ao maior comedor de Helenas da teledramaturgia. [...] a quantidade de citações para \#zemayerfacts no Twitter ultrapassou as dez mil na última quarta-feira [...]. A brincadeira com a fama do ator sexagenário chegou ao mainstream ao entrar para o segundo lugar dos trending topics. Tornou-se pauta da Folha, da Época e até do The Guardian. Aproveitando o hype, Paulo Seabra abriu, rapidamente, um site exclusivo para abrigar as contribuições populares.

Tudo porque Zé Mayer não tem Twitter pois todo mundo sabe a resposta dele para "What are you doing?”. Zé Mayer não conta carneirinhos, conta Helenas. Don Juan se deitou com mil mulheres; Zé Mayer que passou o telefone delas. Maria era virgem porque José não era Mayer. Deviam mudar o nome do jogo Pac-Man pra Pac Mayer. Quando jovem, Zé Mayer gostava de escrever em seu diário, que mais tarde ficou conhecido como "Kama Sutra". Não foi à toa que a revolução sexual aconteceu nos anos 60, quando Zé Mayer atingiu a puberdade. Novelas com o Zé Mayer não duram mais que 9 meses por conta da epidemia de licenças-maternidade

6 Disponível em: < goo.gl/bFaLWv>. Acesso em: 22 jul. 2017.

7 Cf.: vídeo com cenas da novela e entrevista com o ator em: <goo.gl/Liu9cx>. Acesso em: 22 jul. 2017.

$128 \frac{\text { Comunicação \& Inovação, PPGCOM/USCS }}{\text { v. 18, n. 38 (122-140) set-dez } 2017}$ 
no elenco. Segundo a Teoria da Relatividade, Zé Mayer pode pegar você ontem. [...] Na casa do Zé Mayer nem o azeite é virgem. A primeira Helena que Zé Mayer pegou foi a Helena de Tróia. Se você falar Zé Mayer três vezes, você perde a virgindade. (MARMOTA, 2009) ${ }^{8}$

O \#zemayerfacts e os comentários em torno do assunto tratam com ironia o tipo conquistador. Se entre alguns grupos de homens ser "garanhão" é um traço positivo e digno de admiração, a fabulação cotidiana começa a enxergar o machismo que alimenta a construção do tipo e suas narrativas. Começa a surgir a necessidade de desvincular o "galã" do "pegador", das condutas machistas que ficarão para o tipo de masculinidade que a telenovela condena: a do machismo tóxico que leva à dominação e violência ${ }^{9}$.

Em Viver a vida, Zé Mayer é Marcos. A paixão entre ele e Helena acontece à primeira vista, logo nos primeiros capítulos acontece o casamento e a lua de mel em Paris. Ele já pensa em ter filhos com a nova esposa, apesar da diferença de idade, mas o par amoroso de Helena não será Marcos, e sim Bruno (Thiago Lacerda). Por que Marcos e Helena não podem ter um final feliz? O que os impede? Seus obstáculos não parecem ser a diferença da idade, a raça ou a classe social. É a convivência que não dá certo, a relação conflituosa da filha e da ex-mulher com Helena e, sobretudo, o machismo de Marcos.

Ele prefere e faz pressão para que a "mulher dele não trabalhe", uma modelo de sucesso internacional. Mas não é apenas essa a característica machista do personagem. Outro personagem, Gustavo (Marcello Airoldi), amigo e braço-direito do galã, nos ajuda a observar a masculinidade de Marcos. Gustavo é o típico cafajeste, é aquele cara casado mas, sendo homem, "gosta de variar". Ele tem o hábito de passar cantadas em mulheres desconhecidas, corteja a prima da própria esposa, assedia a secretária e a empregada doméstica. Mas ele não é um galã. Ao contrário, Gustavo é o toque de humor da narrativa, o bobo, um palhaço trapalhão: todas as suas investidas dão em frustração. Marcos, que teria ensinado a ele todos os truques da conquista, jura ter se regenerado, mas o homem fiel durou apenas alguns meses. Os personagens nos mostram como o tipo "pegador" declina na telenovela, que sublinha o ridículo do conquistador e do infiel.

8 Vale entrar no blog para ver que o meme que acompanha o dossiê exalta uma característica marcante do galã: o olhar irresistível de conquistador.

9 De acordo com IBGE (HOMENS... 2011), os homens jovens são os que mais morrem em decorrência de violência. Disponível em: <goo.gl/vFoVs6>. Acesso em: 15 jul. 2017. No Brasil, a cada uma hora e meia uma mulher é assassinada por um homem. A Lei do Feminicídio é recente, foi aprovada em 2015. Disponível em: <goo.gl/ZLgbqD>. Acesso em: 22 jul. 2017. De acordo com o Mapa da Violência no Brasil, edição 2015, o país ocupa a $5^{\mathrm{a}}$ posição num ranking de 83 países dentre aqueles que mais registram homicídios femininos. Conferir o Dossiê violencia contra as mulheres elaborado pelo Instituto Patrícia Galvão. Disponível em: $<$ goo.gl/B6JQfg>. Acesso em: 22 jul. 2017. As telenovelas brasileiras tematizam a violência contra a mulher pelo menos a partir de 2003 na telenovela Mulheres apaixonadas (21h), de Manoel Carlos. 
Através da ridicularização de Gustavo, da caracterização de Marcos como um homem machista - mandão e grosseiro, sendo gentil apenas quando tem segundas intenções - e da comparação que surge entre pai, Marcos, e filho, Bruno, o autor descarta um modelo de homem, rotulando-o de anacrônico e ridículo, e propõe outro tipo: um que enxergue a mulher a seu lado, e não um que a tome por objeto ou queira moldá-la. Ao ver se formar o par Helena e Bruno, confirma-se que a transformação da masculinidade foi narrada, representada.

Além da pesquisa sobre o histórico de personagens interpretadas pelo ator, foi importante observar a polêmica que se instaurou a partir da denúncia de assédio feita por uma figurinista da Rede Globo ${ }^{10}$, que gerou muita fabulação na imprensa e nas redes sociais. Agora, não será o personagem na berlinda, mas o ator.

Como se pode conferir nas matérias consultadas, a primeira declaração de José Mayer após a denúncia foi a de que estariam confundindo ficção e realidade. Em A lei do amor (Maria Adelaide Amaral e Vincent Villari, TV Globo, 2016-2017, 21h), José Mayer interpretava o seu primeiro vilão nas telenovelas, Tião, que segundo registrou o blog de Patrícia Kogut hospedado n'O Globo em entrevista com o ator:

Ainda que a trama resgate o galã pegador, que marcou sua trajetória, Mayer acredita que o papel lhe dá a chance de seguir outros caminhos:

- A primeira desconstrução foi com Pereirinha, de "Fina estampa", bem populacho. Repeti a surpresa com Cláudio, de "Império", que quebrou a imagem do macho (ele era gay). Poderia causar estranheza, mas a admiração cresceu, me acharam corajoso. Agora vivo meu primeiro homem mau no horário nobre. Nunca fui maltratado na rua. Será que isso mudará com Tião? (SANTIAGO, 2016)

Vale ressaltar que não está em estudo a conduta do ator, tampouco se pretende aqui expor, julgar ou avaliar "certos" e "errados"; "bons" e "maus", mas observar e perceber, pelas fabulações cotidianas, que há diferentes narrativas que concorrem à versão de verdade da história e que a lógica discursiva da telenovela pode ter penetrado nos discursos do ambiente social e ajudado a determinar uma sanção para o ator, que foi afastado da telenovela: “A TV Globo decidiu suspender o ator José Mayer de qualquer produção dos Estúdios Globo por tempo indeterminado"11. Funcionários, colaboradores, artistas, atrizes

10 Su Tonani (Susllem Meneguzzi Tonani) publicou uma carta no blog “Agora é que são elas", reproduzida em: $<$ goo.gl/hkRZKH>. Acesso em: 12 jul. 2017.

11 Site do G1. Disponível em: <goo.gl/yQMZYG>. Acesso em: 12 jul. 2017; <goo.gl/MtLi4s>. Acesso em: 12 jul. 2017. 
e atores aderiram à campanha "Mexeu com uma, mexeu com todas" 12 . A emissora pediu desculpas à figurinista assediada e a nota foi lida no Jornal Hoje. O Vídeo Show recebeu atrizes para falar sobre a campanha ${ }^{13}$. José Mayer escreveu uma nota se desculpando. Justificou-se:

Tristemente, sou sim fruto de uma geração que aprendeu, erradamente, que atitudes machistas, invasivas e abusivas podem ser disfarçadas de brincadeiras ou piadas. Não podem. Não são.

Aprendi nos últimos dias o que levei 60 anos sem aprender. $\mathrm{O}$ mundo mudou. E isso é bom. Eu preciso e quero mudar junto com ele.

Este é o meu exercício. Este é o meu compromisso. Isso é o que eu aprendi.

A única coisa que posso pedir a Susllen, às minhas colegas e a toda a sociedade é o entendimento deste meu movimento de mudança.

Espero que este meu reconhecimento público sirva para alertar a tantas pessoas da mesma geração que eu, aos que pensavam da mesma forma que eu, aos que agiam da mesma forma que eu, que os leve a refletir e os incentive também a mudar.

Eu estou vivendo a dolorosa necessidade desta mudança. Dolorosa, mas necessária.

O que posso assegurar é que o José Mayer, homem, ator, pai, filho, marido, colega que surge hoje é, sem dúvida, muito melhor. (GLOBO..., 2017. Grifos nossos).

Já foi registrada (JAKUBASZKO, 2010; JAKUBASZKO; NEMI NETO, 2016) certa pluralidade, uma ampliação no espectro das representações das masculinidades e podemos encontrar protagonistas menos idealizados, que já apresentam rupturas com a representação da masculinidade hegemônica. Ainda assim, a questão sobre o valor da fidelidade de nossa cultura, confirmado por Goldenberg (2006), se mantém inalterada. O herói pode ser conquistador até encontrar a sua amada, depois do compromisso seria falha imperdoável. Há muitas sanções à infidelidade nas telenovelas e embora as mulheres sejam punidas sempre com maior rigor, os homens virtuosos também precisam se desculpar pelas traições. O macho sedutor e infiel é normalmente vilão ou bufão. Desse modo, na telenovela o comportamento é ridicularizado, portanto, rejeitado como traço de masculinidade a ser seguida.

Essa foi a lógica que se projetou na imagem do ator José Mayer, casado, enquanto interpretava um vilão e descortinou-se a prática de assediar mulheres ${ }^{14}$. Não foram as

12 Disponível em: <goo.gl/v8TfFY>. Acesso em: 12 jul. 2017.

13 Disponível em: <goo.gl/dCg6wu>. Acesso em: 22 jul. 2017.

14 Especulou-se que ambos teriam um caso, fato que foi desmentido. Disponível em: $<$ goo.gl/91awNn $>$. Acesso em: 20 jul. 2017. Outras atrizes revelaram ter sido assediadas por Mayer. Disponível em: <goo.gl/ds2qaF>. 
maldades de Tião que provocaram a agressividade da audiência, mas as declarações e o machismo do próprio ator. A história seguiu repercutindo na imprensa até que a figurinista retirou a acusação de assédio ${ }^{15}$. José Mayer foi muito criticado e cobrado pelas declarações ambíguas e confusas ${ }^{16}$ até finalmente publicar a carta em que pede desculpas. A emissora se posicionou de forma congruente com o discurso que veicula em suas telenovelas, recriminando o assédio e desculpando-se com a funcionária. As ações institucionais convergiram com o logos pedagógico da telenovela.

Em outros momentos a emissora também mostrou coerência. Repercutiu nas redes sociais que Otaviano, apresentador do Vídeo show, teria sido suspenso após ter provocado reações negativas nas redes sociais por um comentário machista ${ }^{17}$. $\mathrm{O}$ cantor Victor, da dupla sertaneja Victor \& Leo, também pediu afastamento do programa dominical The Voice Kids após ser acusado de violência contra a mulher pela esposa, e a Globo se pronunciou oficialmente:

Esta semana aconteceu um fato importante envolvendo um dos técnicos aqui do nosso programa. Uma acusação bastante grave de violência doméstica envolvendo o Victor. A Globo repudia toda e qualquer forma de violência e acredita que essa acusação precisa ser apurada com rigor, garantindo o direito de defesa na busca da verdade. O Victor inclusive nos procurou, informando que iria se afastar do programa, para se dedicar totalmente a esse caso. (ANDRÉ..., 2014)

$\mathrm{Na}$ ficção, localizamos duas telenovelas recentes que fizeram inserções em que as mulheres mentiam ser vítimas de assédio. Os registros de Rock Story (Maria Helena Nascimento, TV Globo, 2016-2017, 19h) e Força do querer (Glória Perez, TV Globo, 2017, 21h) estão no blog de Nilson Xavier ${ }^{18}$, que sublinha a autoria feminina das tramas. Em Novo Mundo (Thereza Falcão e Alessandro Marson, TV Globo, 18h) o assédio realmente aconteceu: o personagem histórico Dom Pedro (Caio Castro), fazendo jus à sua fama de "conquistador", assediou Anna Millman (Isabelle Drummond) beijando-a à força, em uma novela das $18 \mathrm{~h}^{19}$. Fazemos o registro, mas deixamos para um artigo futuro a análise das representações de assédio nas telenovelas.

Acesso em: 20 jul. 2017.

15 Em carta, a figurinista explica a retirada da acusação. Disponível em: <goo.gl/ETynw8>. Acesso em: 20 jul. 2017.

16 Histórico do caso de assédio. Disponível em: <goo.gl/YohouZ>. Acesso em: 22 jul. 2017.

17 Cf.: <goo.gl/nyHorv>. Acesso em: 20 jul. 2017; <goo.gl/2kprFp>. Acesso em: 20 jul. 2017.

18 Disponível em: <goo.gl/hbU28L > Acesso em: 22 jul. 2017.

19 Cf.: <goo.gl/fKe4au>. Acesso em: 22 jul. 2017; <goo.gl/GwTDiK>. Acesso em 22 jul. 2017.

132 Comunicação \& Inovação, PPGCOM/USCS 
O assédio está na pauta do dia, e diversos casos semelhantes ocorrem cotidianamente sem que os "machos" envolvidos sofram qualquer sanção, a não ser comentários indignados nas redes sociais. O caso mais recente envolveu dois apresentadores do SBT durante o conhecido programa do Sílvio Santos no SBT. Em um de seus quadros dominicais, Maísa foi fortemente assediada por seu colega de televisão, Dudu Camargo. De acordo com a mídia impressa, após as gravações, Maísa deixou o palco, uma produtora foi demitida e Dudu Camargo teve sua carreira alavancada, participando de vários programas de televisão ${ }^{20}$.

Em outro caso, internacional, vale lembrar o recente Oscar dado ao ator americano Casey Affleck pelo filme "Manchester by the sea", dirigido por Kenneth Lonergan. Affleck foi acusado de assédio sexual (em situação semelhante à do ator José Mayer) por produtoras de um filme em que ele trabalhara anteriormente. Tudo foi resolvido em segredo de justiça. Porém, durante a sua premiação em 2017, a atriz Brie Larson, que lhe entregou o Oscar, fez um protesto em silêncio recusando-se a aplaudir a entrega do prêmio. São apenas dois dentre inúmeros exemplos que contradizem cotidianamente as representações que as telenovelas vêm construindo para narrar e propor possíveis soluções em direção à equidade de gênero. A disputa está em processo e a figura do galã aparece como modelo em vias de transformação.

O galã de novela é um tipo indispensável à roteirização do folhetim eletrônico e suas alterações composicionais ao longo do tempo podem revelar muito sobre o desenvolvimento do próprio gênero teledramatúrgico, assim como sobre o machismo e as representações das masculinidades na cultura brasileira. Suas representações certamente terão que se adaptar às mudanças no contexto sociocultural. Já existem hipóteses e comprovações sobre como a telenovela tem se aliado à democratização nas relações de gênero (JAKUBASZKO, 2010; JAKUBASZKO; NEMI NETO, 2016).

As telenovelas narram histórias feministas, num esforço progressista e civilizador, para cumprir com o logos pedagógico da novela, refratam na direção da verdade e da justiça, mas também deixam escapar os reflexos de uma cultura machista. Nem sempre a audiência capta esse reflexo e não se produz qualquer fabulação no cotidiano. Como exemplo podemos citar o episódio de 10 de abril de 2017 da telenovela Força do querer (Glória Perez, TV Globo, 2017, 21h): o personagem Zeca (Marco Pigossi) retira Ritinha (Isis Valverde) à força do aquário em que ela trabalhava por não concordar com seu emprego de sereia. Em uma cena brutal, mas que se pretendia cômica ${ }^{21}$, o galã carrega nos ombros

20 Disponível em: <goo.gl/TscZ3r>. Acesso em: 12 jul. 2017; <goo.gl/auNvfN>. Acesso em: 12 jul. 2017.

21 Vale relembrar o trecho que grifamos da carta de José Mayer: "atitudes machistas, invasivas e abusivas podem ser disfarçadas de brincadeiras ou piadas. Não Podem". 
a sua namorada enquanto ela se debate, pedindo para ficar em seu emprego. Ainda em 2017 é possível ver a telenovela reproduzir a já tradicional cena - tão comum em tantas telenovelas ao longo da história - do homem infantilizando a mulher, retirando a agência da heroína em nome do amor, ou da moral e dos bons costumes. Interessante lembrar ainda que Pedro (José Mayer), em Laços de família (Manoel Carlos, TV Globo, 20002001, 21h), ao longo da novela, bateu na personagem Íris (Deborah Secco) ${ }^{22}$. Também é interessante notar que os registros de audiência marcam aumento nos capítulos em que mulheres apanham ou batem umas nas outras motivadas por ciúme ou por reparação/ vingança, principalmente por infidelidade.

Ao estudar como os romances assimilam o tempo-espaço histórico e constroem a imagem do homem desse tempo representado, Bakhtin (2006) discorre sobre o romance de formação do tipo realista, que, acreditamos, aproxima-se de alguns aspectos da teledramaturgia brasileira. Diferente de outros tipos de romances de formação que representam o tempo histórico apenas como um pano de fundo, as narrativas dos romances realistas de formação apresentam seus heróis e conflitos de modo indissolúvel com o tempo histórico.

O homem se forma concomitantemente com o mundo, reflete em si mesmo a formação histórica do mundo. O homem já não se situa no interior de uma época, mas na fronteira de duas épocas, no ponto de transição de uma época a outra. Essa transição se efetua nele e através dele. Ele é obrigado a tornar-se um novo tipo de homem, ainda inédito. Trata-se precisamente da formação do novo homem [...] mudam os fundamentos do mundo, cabendo ao homem mudar com eles. Compreende-se que nesse romance de formação surjam em toda a sua envergadura os problemas da realidade e das possibilidades do homem, da liberdade e da necessidade, os problemas da iniciativa criadora. (BAKHTIN, 2006, p. 222)

A supersérie Os dias eram assim (Angela Chaves e Alessandra Poggi, TV Globo, 2017, 23h) parece cuidar atentamente das contradições do tema. O capítulo de 21 de julho de 2017, por exemplo, aprofunda o conflito de dois casais: Alice (Sophie Charlotte) e Renato (Renato Góes) se apaixonaram, mas seus cônjuges não querem conceder a separação. Ao mesmo tempo em que a trama resgata um contexto histórico-político brasileiro, da luta contra a repressão e a ditadura militar, mostra as transformações na intimidade. Entrelaçando tempo histórico e construção de personagem, a ficção mostra como a democratização da vida privada está diretamente relacionada à democratização da vida pública, conforme observa Giddens (1993). Para o autor, a sexualidade está diretamente ligada à reelaboração da narrativa do eu; da autoidentidade; da democratização da vida cotidiana

22 Disponível em: <goo.gl/rc3utJ>. Acesso em: 20 jul. 2017. 
que anda em sintonia com a democratização da esfera pública. As práticas democráticas na vida pessoal estimulam práticas sociais igualmente democráticas: "Num plano mais amplo, existe uma simetria entre a democratização da vida pessoal e as possibilidades democráticas na ordem política global" (GIDDENS, 1993, p. 213). A supersérie dialoga com o momento político atual brasileiro e vem sendo elogiada por não utilizar o contexto histórico apenas como pano de fundo ${ }^{23}$. Inclusive esteticamente ao retomar fotos e vídeos da época. É a ficção se entrelaçando ao histórico e aos tempos passado e presente, com projeções para o futuro.

Em Os dias eram assim, a temática dos estigmas da separação e do desquite, já superados na atualidade, marca uma leitura do passado que identifica o comportamento machista com a lógica patriarcal e autoritária, apontando para as forças progressistas da sociedade como as responsáveis pelo esforço em direção à democratização das relações. Destacam-se as referências a Leila Diniz, ao semanário O Pasquim, a Salvador Allende. Sem cair no estereótipo, o machismo também se pratica por meio da mulher, já que Rimena (Maria Casadevall), esposa de Renato, se recusa a dar a separação e quer manter o casamento à força, tanto que pretende engravidar de outro homem para manter seu casamento. Do mesmo modo, o marido de Alice, Vitor (Daniel de Oliveira), não quer aceitar o fim do casamento apesar de ter, ele próprio, uma amante. É a representação do "macho, adulto, branco, sempre no comando" e pronto a tratar uma mulher como objeto. A minissérie também faz referência às leis de honra ainda em vigor na época, marcando quão machista era a visão de mundo em relação ao presente. Alice pode perder a guarda das crianças caso aja de maneira "imoral", como bem sublinhado por seu advogado. Já seu marido Vitor - mesmo com amantes, sendo usuário de drogas - sabe que a lei está ao seu lado em caso de separação e não hesitará em exercer seu poder. Se os dias eram assim antigamente, por que não perguntar: atualmente a masculinidade está mesmo mudando?

A ficção televisiva seria um gênero em zona de fronteira entre o machismo e o feminismo? Na telenovela, a trajetória do par amoroso que vence sucessivos obstáculos para atingir a união no fim da história é o fio melodramático que conduz a narrativa e ajuda a entrelaçar a estrutura de vários núcleos dramáticos, apresentando as diversas ações e histórias que irão preencher o hiato de tempo em que os heróis vivem separadamente (CAMPEDELLI, 1987; PALLOTTINI, 1998). O final feliz se manifesta na profusão de casamentos na última semana, principalmente no último capítulo. $O$ ponto de chegada, portanto, é a recompensa dos virtuosos e a punição, ou regeneração, dos vilões. A união amorosa coroa o ciclo da recompensa. A solidão costuma ser uma punição. Nesta fórmula

23 Cf.: <goo.gl/LjxgeQ>. Acesso em: 20 jul. 2017; <goo.gl/pQYgxd>. Acesso em: 20 jul. 2017. 
ainda vige o amor romântico. Entretanto, seu viés machista vem sendo questionado, ainda que reproduzido em alguns casos como vimos na novela atual $A$ força do querer (Glória Perez, TV Globo, 2017, 21h).

O amor romântico a que nos referimos é aquele que aparece nos finais do século 18 com as novelas, romances e, mais tarde, com o cinema. O "início do amor romântico coincidiu mais ou menos com a emergência da novela" (GIDDENS, 1993, p. 50) e estava integrado com a criação do lar, com as modificações nas relações entre pais e filhos e com a "invenção da maternidade". Temos que lembrar que a paixão (amour passion) não fazia parte dos casamentos, e a emergência do amor romântico traz alento às mulheres e impulso para as transformações da intimidade, com contradições:

O amor romântico era essencialmente um amor feminilizado. Como revelou Francesca Cancian, antes do final do século XVIII, se de algum modo se falava de amor em relação ao casamento, tratava-se de um amor de companheiros, ligado à responsabilidade mútua de maridos e esposas pelo cuidado da família ou da propriedade. Por isso, em The Well-Ordered Family, publicado logo após a virada do século, Benjamim Wadsworth declarou sobre o casal casado que "o dever do amor é mútuo, deve ser realizado de um para o outro". Entretanto, com a divisão das esferas de ação, a promoção do amor tornou-se predominantemente tarefa das mulheres. As ideias sobre o amor romântico estavam claramente associadas à subordinação da mulher ao lar e ao seu relativo isolamento do mundo exterior. Mas o desenvolvimento de tais ideias foi também uma expressão do poder das mulheres, uma asserção contraditória da autonomia diante da privação. (GIDDENS, 1993, p. 54)

Dentre as principais características do amor romântico estão a completude que os parceiros trazem um ao outro; a história de vida compartilhada pelo casal; a diferenciação do relacionamento conjugal de outros aspectos da organização familiar, de modo que ele ganha prioridade e atenção especial. O amor romântico é mantido "pela associação do amor com o casamento e com a maternidade; e pela ideia de que o amor verdadeiro, uma vez encontrado, é para sempre" (Ibid., p. 58). Desse modo, quer ser indissolúvel. O amor idealizado é um "encontro de almas": ele preenche o vazio do indivíduo que, se antes estava fragmentado, agora passa a se sentir inteiro. O processo tem fortes laços com a autoidentidade: "No amor romântico, a absorção pelo outro [...] está integrada na orientação característica da 'busca'. A busca é uma odisseia em que a autoidentidade espera a sua validação a partir da descoberta do outro" (Ibid., p. 57). O amor romântico coloniza o futuro e ajuda a construir a autoidentidade.

É exatamente este tipo de amor que ainda, acreditamos, encontra-se nas telenovelas. Os casais se unem no êxtase de completarem-se um ao outro. Toda a história dos 
protagonistas, se resume numa busca por aquele(a) que proporcionará a plenitude, o sentido mesmo da sua existência. A usual punição de deixar as mulheres sem par amoroso no final da novela, por exemplo, é uma forma de valorizar hierarquias entre as mulheres cujo critério é ser a "posse" de um macho, como se a mulher só tivesse valor se casada. As narrativas que exaltam o amor romântico, monogâmico, podem estimular uma visão de mundo de forte viés machista. "A solidão, para algumas mulheres, está associada à vergonha, pois, no Brasil, ser uma mulher sem homem é sinal de fracasso. Para outras, estar só é estar desprotegida e insegura, sobretudo economicamente” (Ibid., p. 30).

Neste ponto, a telenovela A favorita (João Emanuel Carneiro, TV Globo, 2009, 21h) inovou e acertou no final de Catarina (Lilia Cabral) que, cansada da violência doméstica depois de tanto tentar agradar ao marido, preferiu a separação, a emancipação e no final recusou o pedido de casamento que recebera de um pretendente. Ela escolheu viver sozinha. A solidão foi a sua recompensa.

Por muito tempo os protagonistas atuaram como representantes do padrão hegemônico, as mudanças são muito recentes. Namoros que seguem e acabam, divórcios, novos arranjos familiares, histórias de amores puros e confluentes (GIDDENS, 1993), heterossexuais e homossexuais, assim como formações poliamorosas nas tramas secundárias. E as mudanças avançam para as tramas principais, colocando em questão o machismo do amor romântico e se atualizando em relação ao tempo histórico presente.

Talvez o caso mais recente de mutação do amor romântico heterossexual tenha sido o final de Félix (Mateus Solano) em Amor à vida (Walcyr Carrasco, TV Globo, 20132014, 21h). Amparado pelo público, o autor deu ao personagem um final feliz com Niko (Thiago Fragoso). O protagonismo do par amoroso heterossexual foi apagado pelo brilho da história de amor entre Félix e Niko, garantindo aos dois homens a última união amorosa da trama a se consolidar - aquele lugar de honra reservado aos personagens principais. A narrativa de Félix exemplifica tanto a dificuldade de expor a diferença quanto a revolta com os padrões hegemônicos. Consumou-se o tão esperado "beijo gay" na telenovela e uma explosão de comentários, a maioria em tom de comemoração, explodiu na imprensa e nas redes sociais: o casal gay se tornara o par romântico protagonista da história. A cena final da telenovela mostrava o pai finalmente aceitando o filho independentemente de sua orientação sexual e não um final feliz do par amoroso convencional. Vale registrar que a cena do beijo entre Félix e Niko foi censurada na exibição da telenovela no México $^{24}$. O sucesso da personagem e sua narrativa mostra que a audiência brasileira se identifica com representações que rompem com a heteronormatividade e o machismo.

24 Disponível em: <goo.gl/4GWk9V>. Acesso em: 22 jul. 2017. 


\section{Considerações finais}

Os gêneros, e seu sentido no jogo de significação social, oferecem sentido estruturador para as identidades. A masculinidade é uma construção histórica e social e em permanente transformação. O machismo é a expressão da dominação masculina, como um conjunto de valores, crenças e práticas, que cria hierarquias e alimenta a desigualdade entre os gêneros. A dominação masculina afeta a todos. O sistema das representações de masculinidade das telenovelas trabalha com a expectativa da igualdade entre os gêneros, mas as contradições também se pronunciam.

Será que o galã pode tudo em nome do amor romântico? Personagens como Zeca de $A$ força do querer podem tirar a mulher amada do trabalho em nome da moral e da vergonha contra a sua vontade? Tal ato ainda presente nas novelas ${ }^{25}$ mantém o espaço opressor do macho, porém juntamente com esses momentos de agressão espaços de empoderamento feminino e de minorias se fortalecem.

Quando Gabeira (1980) escreveu O crepúsculo do macho, ele anunciava o final da hegemonia do macho que defendia sua honra com sangue, que subjugava outras espécies e outros gêneros da própria espécie. Contudo, nenhum império termina facilmente ou de maneira abrupta. São necessários anos, às vezes décadas, para que novas estruturas de poder se cristalizem. A "tomada de poder", como a história explica as transições imperiais (Império Romano, Cristianismo, o Império Americano...) torna-se uma tarefa mais difícil. A derrocada do macho vem sendo anunciada há décadas, porém, como todo processo de transição, está composto por movimentos de retração e expansão. O império do macho, ainda que fragilizado, tem experiência no exercício de dominação e subjugação em que minorias tentam não tomar o poder, mas sim expandi-lo e diluí-lo em espaços mais igualitários de representação, deixando espaço aberto para novas possibilidades de ser e estar no mundo. E assim o gênero telenovela vai diluindo a trama principal, trabalhando cada vez mais uma estrutura em múltiplos núcleos dramáticos (multiplot) e troca de protagonismos, retirando os holofotes das representações machistas e transformando os "galãs pegadores" em anacrônicos modelos de masculinidade. O fio condutor passa a ser o amor, mas não necessariamente o modelo romântico ao gosto patriarcal. Os roteiristas da atualidade têm desafios a superar: como desvincular as formas composicionais do galã da representação do amor romântico e das possibilidades de happy ending do machismo que está impregnado na cultura e nos gêneros discursivos?

25 Em nossas observações, em 14 de julho de 2017 na telenovela Pega-pega (Claudia Souto e colaboradores, TV Globo, 2017, 19h), o galã Eric, vivido por Mateus Solano, usa do mesmo recurso de Zeca quando sua namorada, Luíza, interpretada por Camila Queiroz, se recusa a falar com ele. Cf.: <goo.gl/LptD6a>. Acesso em: 20 jul. 2017. 
À medida que surgem modelos alternativos de masculinidade, que as lutas feministas e LGBTQ avançam em suas conquistas, a teledramaturgia precisa se adaptar para continuar dialogando com sua audiência. Agora é esperar pelos próximos capítulos para saber como as formas poéticas vão corporificar um novo galã de novela, e como a diversidade irá crescer e se fixar na representação de contextos históricos, pessoais e de relações afetivas e amorosas.

\section{REFERÊNCIAS}

ANDRÉ Marques informa o afastamaneto de Victor Chaves, da dupla Victor \& Leo, do "The Voice Kids". Gshow, Rio de Janeiro, 26 fev. 2017. Disponível em: <goo.gl/FCvfqz>. Acesso em: 20 jul. 2017. ARAÚJO, T. As primeiras cenas de José Mayer e Klebber Toledo como o casal gay de Império (vídeo) Huffpost News Brasil, 22 jul. 2014. Disponível em: <goo.gl/bFaLWv>. Acesso em: 22 jul. 2017.

BAKHTIN, M. M. Estética da criação verbal. São Paulo: Martins Fontes, 2006.

CAMPEDELLI, S. Y. A telenovela. 2. ed. São Paulo: Ática, 1987.

CAVALCANTE, M. I. Do romance folhetinesco às telenovelas. OPSIS - Revista do NIESC, Goiânia, v. 5, p. $63-74,2005$.

GABEIRA, F. O crepúsculo do macho. Rio de Janeiro: Codecri Pasquim, 1980.

GALÃ. In: DICIONÁRIO Aurélio da língua portuguesa. Curitiba: Positivo, 2014

GIDDENS, A. As transformações da intimidade: sexualidade, amor e erotismo nas sociedades modernas. São Paulo: Unesp, 1993.

GLOBO suspende José Mayer; atrizes fazem protesto contra assédio. G1, Rio de Janeiro, 4 abr. 2017. Disponível em: <goo.gl/Dbxvh7> Acesso em: 12 jul. 2017.

GOLDENBERG, M. Infiel: notas de uma antropóloga. Rio de Janeiro: Record, 2006.

HAMBURGER, E. O Brasil antenado: a sociedade da novela. Rio de Janeiro: Jorge Zahar, 2005

HOMENS jovens são os que mais morrem de causas violentas, diz IBGE. G1, São Paulo, 30 nov. 2011. Disponível em: <http://glo.bo/scvsxy> Acesso em: 13 nov. 2017.

JAKUBASZKO, D. Levantamento da presença de temas de importância social nas telenovelas brasileiras. In: CONGRESSO BRASILEIRO DE CIÊNCIAS DA COMUNICAÇÃO, 31., 2008, Natal. Anais... Natal: UFRN, 2008. p. 56-73

A construção dos sentidos da masculinidade na telenovela A Favorita: um diálogo entre as representações da masculinidade na telenovela e as representações das manifestações discursivas do ambiente social brasileiro. 2010. 346 f. Tese (Doutorado em Ciências da Comunicação) - Escola de Comunicações e Artes, Universidade de São Paulo, São Paulo, 2010.

JAKUBASZKO, D.; NEMI NETO, J. A representação das masculinidades na telenovela brasileira: há espaço para um novo espectro de masculinidades? In: CONGRESO LATINOAMERICANO DE 
INVESTIGADORES DE LA COMUNICACIÓN, 13., 2016, Cidade do México. Anais... Cidade do México: UAM, 2016.

LOPES, M. I. V.; GÓMEZ, G. O. (Orgs.). (Re)invenção de gêneros e formatos da ficção televisiva: anuário Obitel 2016. Porto Alegre: Sulina, 2016.

MARMOTA, A. Dossiê José Mayer: por que ele merece o \#zemayerfacts. Marmota mais dos mesmos, 19 set. 2009. Disponível em: <goo.gl/opZ9j8>. Acesso em: 12 jul. 2017.

MARTÍN-BARBERO, J. Dos meios às mediações: comunicação, cultura e hegemonia. Rio de Janeiro: UFRJ, 2015.

MOTTER, M. L. A telenovela: documento histórico e lugar de memória. Revista USP, São Paulo, n. 48, p. 74-87, dez./fev. 2000-2001.

. Fiç̧ão e realidade: a construção do cotidiano na telenovela. São Paulo: Alexa Cultural, Comunicação \& Cultura, 2003.

Mecanismos de renovação do gênero telenovela: empréstimos e doações. In: LOPES, M. I. V. Telenovela: internacionalização e interculturalidade. São Paulo: Loyola, 2004. p. 251-292.

NEMI NETO, J. Anthropophagic queer: a study on abjected bodies and brazilian queer theory. 2015. $246 \mathrm{f}$. Tese (Doutorado em Filosofia) - Faculty in Hispanic and Luso-Brazilian Literatures and Languages, The City University of New York, New York, 2015.

. Effeminacy and queer representation in Brazilian telenovelas. In: BRAZILIAN STUDIES ASSOCIATION, 13., 2016, Providence. Anais... Providence: Brown University, 2016.

PALLOTTINI, R. Dramaturgia de televisão. São Paulo: Moderna, 1998.

SANTIAGO, A. L. Vilão de "A Lei do Amor”, José Mayer fala de audiência. O Globo, Rio de Janeiro, 13 nov. 2016. Patrícia Kogut. Disponível em: <goo.gl/Z1wEcG> Acesso em: 22 jul. 2017.

SER galã é função ingrata, diz José Mayer. Bol Notícias, São Paulo, 22 set. 2009. Disponível em: <goo.gl/ bY3mxp>. Acesso em: 20 jul. 2017. 